
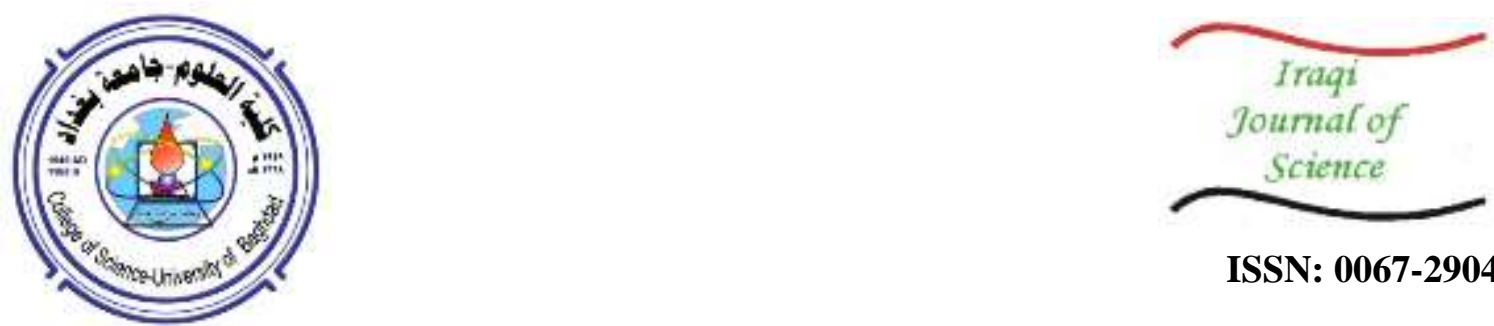

ISSN: 0067-2904

\title{
Comparison of Some Physiological Parameters in Female Rheumatoid Arthritis Patients in Pre- and Postmenopausal Stages
}

\author{
Noorhan H. Yousif *, Shaima R. Ibraheem \\ Department of Biotechnology, College of Science, University of Baghdad, Baghdad, Iraq
}

Received: 19/12/2019 Accepted: 5/4/2020

\begin{abstract}
Rheumatoid arthritis is an autoimmune disorder that is highly prevalent, leading to gradual cartilage distraction, and therefore is important to diagnose in the early stage. This study aimed to estimate the level of rheumatoid factor (RF) and Anticitrullinated protein (Anti-ccp) in the serum of female patients. We also investigated several female reproductive hormones in the patients and compared their levels in the premenopausal and postmenopausal phases. The study included 88 female subjects, 50 suffering from signs of rheumatoid arthritis who were attending ALYarmouk teaching hospital, Baghdad, Iraq, and 38 without clinical signs of RA as a control group. The ELISA technique was used to estimate all the studied parameters. The results showed a significant elevation in the levels of RF (103.6 \pm 227.0 vs. 22.1 $\pm 111.0 \mathrm{U} / \mathrm{ml})$ and Anti-ccp $(158.0 \pm 170.0$ vs. $0.51 \pm 1.69 \mathrm{U} / \mathrm{ml})$ in patient's serum as compared to the control. The percentage of overweight and obese patients was higher than that of those with normal weight. Also, the current results showed significant differences in the serum concentrations of the reproductive hormones between the premenopausal and postmenopausal phases in the patients group. The level of FSH in postmenopausal female patients was higher than that in premenopausal ones $(33.5 \pm 17.9$ vs. $9.01 \pm 9.31 \mathrm{U} / \mathrm{ml})$. Also, the level of luteinizing hormone (LH) in the postmenopausal patients was higher than that in the premenopausal patients $(26.4 \pm 12.3$ vs. $12.7 \pm 10.2 \mathrm{U} / \mathrm{ml})$. While the level of prolactin (PRL) in RA postmenopausal female patients was lower than that in the premenopausal patients $(8.60 \pm 7.07$ vs. $14.8 \pm 10.6 \mathrm{ng} / \mathrm{ml})$. In addition, the level of Anti-mullerian hormone (AMH) in post-menopausal patients was lower than that in the pre-menopausal ones $(0.034 \pm 0.023$ vs. $0.635 \pm 0.683 \mathrm{ng} / \mathrm{ml})$. Finally, the concentration of estradiol (E2) in the post-menopausal female patients was lower than that in the pre-menopausal ones $(32.9 \pm 18.6$ vs. $76.5 \pm 43.6 \mathrm{ng} / \mathrm{ml})$.
\end{abstract}

Keywords: Rheumatoid arthritis; Anti-ccp; rheumatoid factor; FSH; LH; menopausal phase.

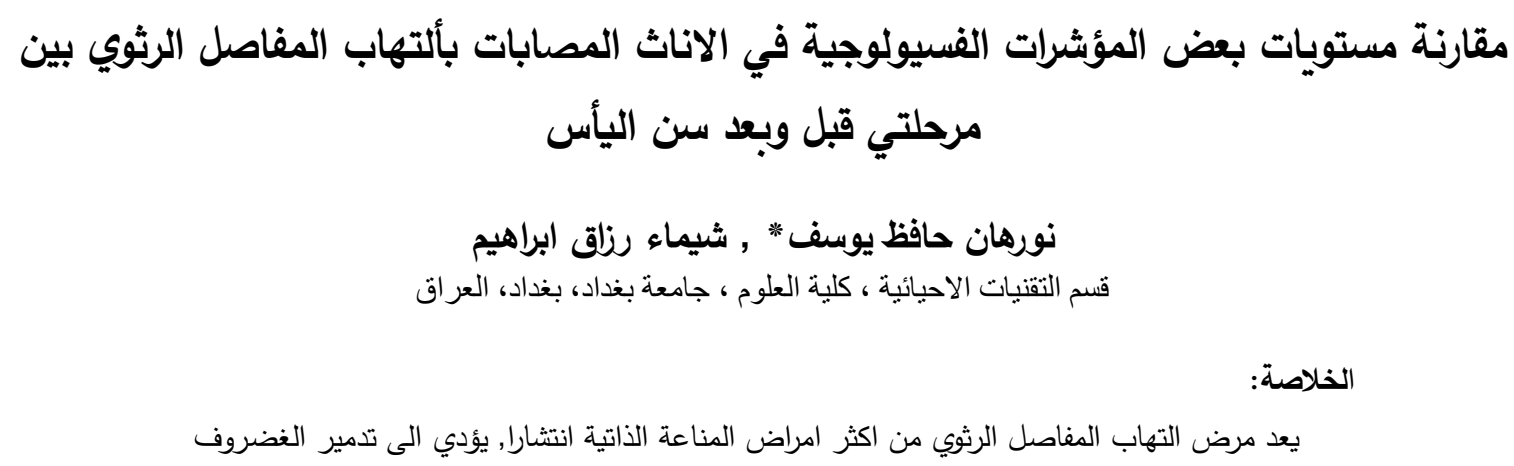

*Email: noorhanhafud@yahoo.com 


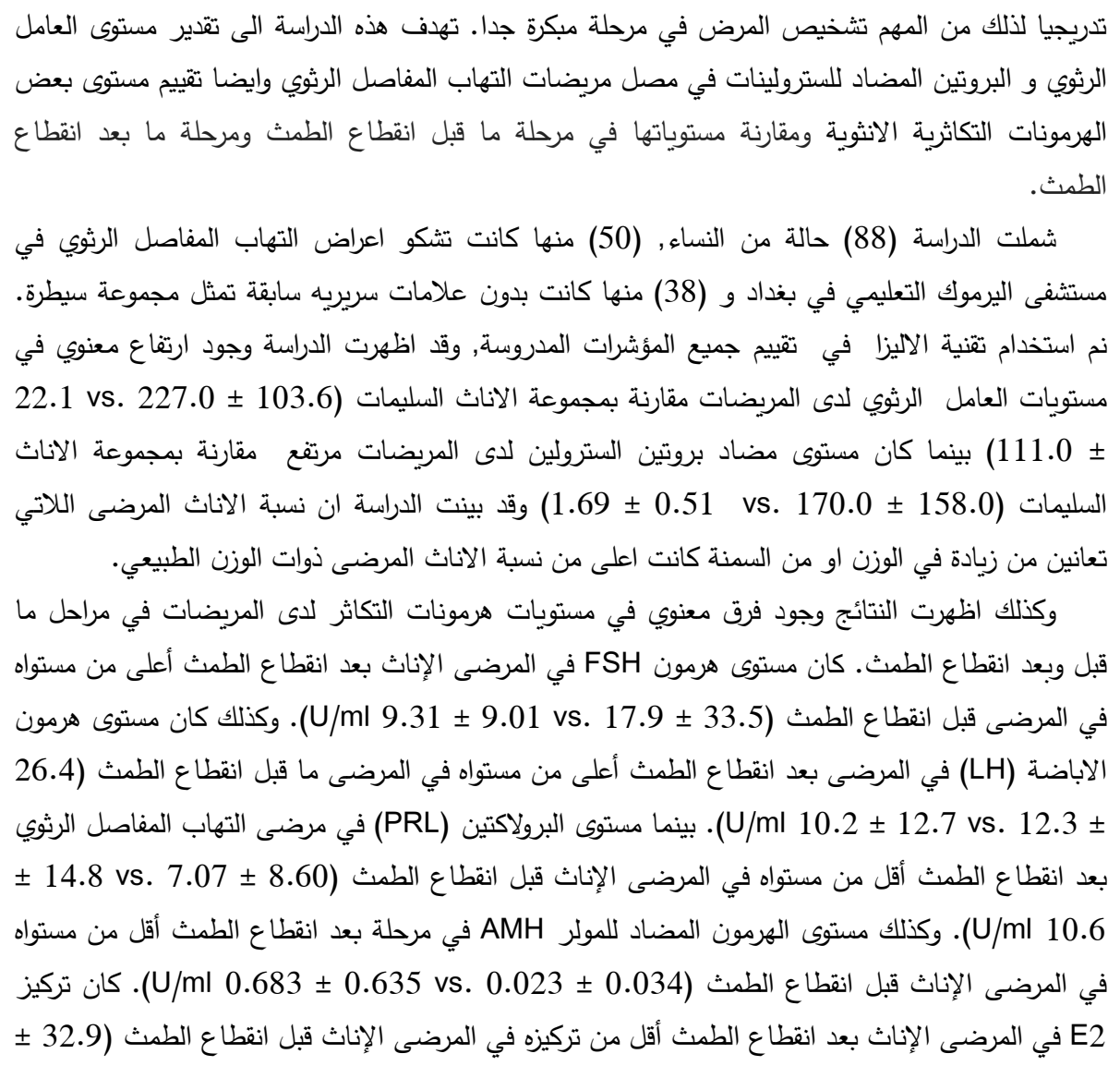

\section{Introduction}

.(U/ml $43.6 \pm 76.5$ vs. 18.6

Rheumatoid arthritis (RA) is a chronic systemic inflammatory autoimmune disorder characterized by a continual joint inflammation leading to cartilage and bone destruction, disability, and eventually to systemic complications [1]. The causative factors are not known while a careful diagnosis has to be made. However, the knowledge of the disease pathogenesis has only led to many recent therapeutics with low impacts [2] . The disease affects women 2 to 3 times more often than men and occurs at any age. The peak prevalence is in the sixth decade. RA of pathophysiology involves chronic inflammation of the synovial membrane, which can destroy the articular cartilage and articular bone [3]. The key pathogenic markers of RA include the rheumatoid factor autoantibody which is directed against the Fc fragment of Immunoglobulin G (IgG) [4]. Anti-citrullinated protein antibody (ACPA) is prognostically and diagnostically useful, with ACPA being positive even years before the start of the disease. [5]. The best approaches for the management of RA are using synthetic or biologic disease-modifying antirheumatic drugs (DMARDs) [6].

Female hormonal factors play a vital role in the development of RA. The study of female hormonal factors is challenging because serum levels may differ throughout a woman's lifetime and interact with various environmental, genetic, immunological, and endocrine factors influencing the development of autoimmunity.[7]. Pregnancy may be related to lower disease activity in half of the women, but the postpartum period is associated with an increase in the activity in up to $90 \%$ of cases. The first symptoms of the disease have been related to the menopausal period and with an increased risk at the earlier stages of menopause. Some studies suggest that hormonal replacement therapy (HRT) reduces the risk of RA in postmenopausal women [6].

\section{Materials and methods}

Blood Samples collection

The study included 50 patients who suffered from joint pain and attended at AL-Yarmouk teaching hospital/Rheumatology clinic, Baghdad, Iraq. All patients were diagnosed by physicians.

An amount of $5 \mathrm{ml}$ of blood was collected by a disposable syringe and placed in a gel clot activator tube at room temperature until the coagulant was forming. Then the samples were centrifuged at 3000 
rpm for 15 minutes. Serum samples were separated on Eppendorf tubes. All samples were stored at $20^{\circ} \mathrm{C}$ until examined.

The collected serum was used to determine some biochemical and immunological parameters according to the manufacturer's protocols; $\mathrm{RF}(\mathrm{IgG})$ and Anti- ccp (IgG) antibodies were measured as diagnostic tests for the disease using commercially available enzyme-linked immunosorbent assay ( $\mathrm{RF}$ and Anti- ccp kits, Aeskulisa / Germany). FSH, LH, PRL, Estradiol kits (Monobind / USA) and AMH kit (Anshlab, Germany) were measured using enzyme-linked immunosorbent assay (ELISA).

\section{Result and Discussion}

\section{Distribution of the patient groups according to Body Mass Index (BMI)}

The current study showed that the majority of rheumatoid arthritis patients were found to be overweight $(38 \%)$ followed by obese $(36 \%)$ and the normal weight $(26 \%)$ patients, as illustrated in Figure-1.

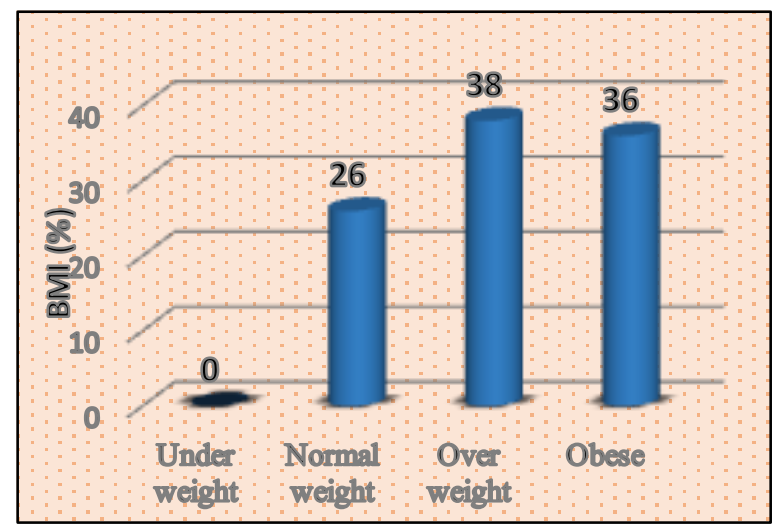

Figure 1-Weight categories percentage for the patient groups. Under weight (below 18.5), normal weight (18.5-24.9), over weight (25-29.9) and, obese (30 and above)

These results agree with those reported by Abass and Ramadhan [8] who noted that overweight patients had the highest percentage among RA patients. Similar observations were reported in two cohort studies $[9,10]$. Excess body weight was considered as a potential contributor to the development of RA [11]. The excess production of adipocytokines, developed primarily by adipose tissues, creates a loop of chronic inflammation due to continuous activation of macrophages, while the white adipose tissues produce TNF- $\alpha$ and IL- 6 . These findings reveal the connection between the chronic inflammatory conditions and the adipose tissue [12].

The level of rheumatoid factor (RF) in the sample groups

In the current study, the level of rheumatoid factor (RF) in the patient groups was higher than its level in the control group. Statistically, a significant difference $(\mathrm{p}<0.05)$ was found in RF level between patient and control groups $(103.6 \pm 227.0$ vs. $22.1 \pm 111.0 \mathrm{U} / \mathrm{ml})$ as illustrated in Figure-2.

The percentage of patients with a positive value of RF was 56\%, while that in the healthy control was 2.6\%. This result agrees with that of Mohammed and coworkers [13] who illustrated that the percentage of RA patients with seropositive RF was higher than that in patients with negative RF.

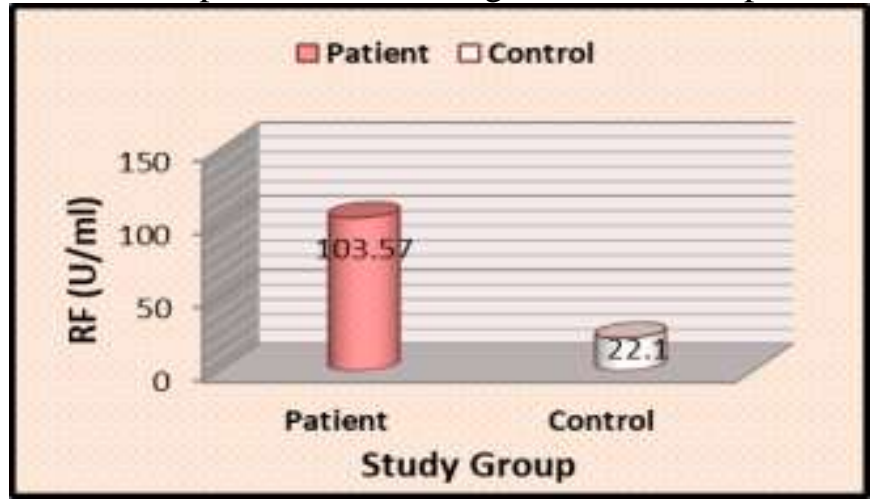

Figure 2-The level of RF in the study groups. 
The percentage of patients with a positive value of Anti-ccp was 78\%, while that in the control was $0 \%$, which agrees with the results reported by Jasim and Ibrahim [14]. A combination of anti-CCP and RF levels is important in the diagnosis of disease and result in the highest sensitivity and specificity. As shown in Figure- 3, the level of Anti-ccp was higher in the patients as compared to controls $(158.0 \pm 170.0$ vs. $0.51 \pm 1.69 \mathrm{U} / \mathrm{ml})$, with highly significant differences $(\mathrm{p} \leq 0.001)$

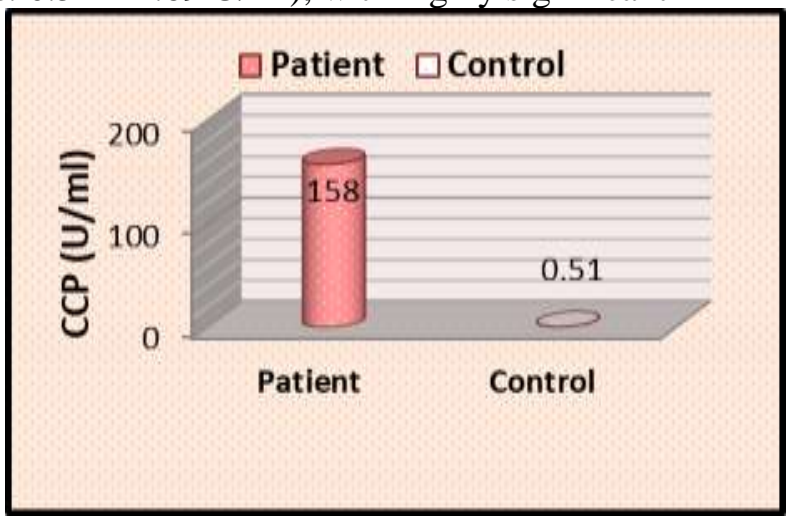

Figure 3-The level of anti-ccp antibodies in the study groups.

There is a proof that early aggressive clinical action in RA patients will delay the progression of the disease and joint damage, leading to a better prognosis. Thus, differentiating between RA and other types of arthritis is important early after the onset of symptoms.

CCP ELISA could be clearly shown to provide the best combination of sensitivity and specificity for detecting RA, with a significant difference between the anti-ccp and RF.

Levels of physiological parameters in pre- and post-menopausal patients:

The current study revealed no significant differences ( $p>0.05$ ) in RF and Anti-ccp levels between pre- and post-menopausal female patients, but the concentration of RF in postmenopausal patients was higher than that in premenopausal ones ( $87 \pm 194$ vs. $121 \pm 256$ ). While the Anti-CCP concentration was higher in premenopausal patients as compared to that in postmenopausal ones (195 \pm 177 vs. 133 \pm 163 ), as shown in Table-1. This result may reveal that RF increases in postmenopausal female patients due to the hormonal changes in this stage. These hormonal changes may have an effect on the Anti-ccp serum level in patients.

Statistically, there were highly significant differences in the levels of FSH between pre- and postmenopausal patients $(\mathrm{p}<0.01)$, as shown in Table-1. The level of FSH in postmenopausal female patients group was higher than its level in premenopausal one $(33.5 \pm 17.9 \mathrm{vs} .9 .01 \pm 9.31 \mathrm{U} / \mathrm{ml})$. This result is consistent with that reported by Ginting et al.[15] who observed that FSH level was increased with aging. In addition, there were highly significant differences $(\mathrm{p}<0.01)$ in the level of LH between both stages $(26.4 \pm 12.3$ vs. $12.7 \pm 10.2 \mathrm{U} / \mathrm{ml})$ as shown in Table-1. This result agrees with that of Cevik et al.[16] who reported that LH had statistically lower concentrations in pre-menopausal RA women. However, the level of prolactin (PRL) in RA postmenopausal female patients was significantly $(\mathrm{p}<0.05)$ lower than that in premenopausal ones $(8.60 \pm 7.07 \mathrm{vs.} 14.8 \pm 10.6 \mathrm{ng} / \mathrm{ml})$.

The anti-mullerian hormone is the best marker for ovarian functional reserve. With aging, the functional capability of ovaries is decreasing, therefore, the serum level of AMH falls continuously in the post-menopausal phase. In this study, there were highly significant differences $(p<0.01)$ in the level of $\mathrm{AMH}$, with lower levels in post-menopausal than in the pre-menopausal patients $(0.034 \pm$ 0.023 vs. $0.635 \pm 0.683 \mathrm{ng} / \mathrm{ml}), \quad$ as shown in Table-1.

Table 1-A comparison between pre- and postmenopausal patient groups in RF and Anti-ccp levels

\begin{tabular}{|c|c|c|c|}
\hline \multirow{2}{*}{ Variable } & \multicolumn{3}{|c|}{ Phases } \\
\hline & Premenopausal & Postmenopausal & $P$-value \\
\hline $\mathrm{RF}(\mathrm{U} / \mathrm{ml})$ & $87 \pm 194$ & $121 \pm 256$ & 0.602 \\
\hline Anti-CCP (U/ml) & $195 \pm 177$ & $133 \pm 163$ & 0.212 \\
\hline FSH ml (U/ ml) & $9.01 \pm 9.31$ & $33.5 \pm 17.90$ & $0.001 * *$ \\
\hline LH ml (U/ml) & $12.7 \pm 10.2$ & $26.4 \pm 12.3$ & $0.001 * *$ \\
\hline PRL (ng/ml) & $14.8 \pm 10.6$ & $8.60 \pm 7.07$ & $0.024 *$ \\
\hline
\end{tabular}




\begin{tabular}{|c|c|c|c|}
\hline E2 $(\mathrm{pg} / \mathrm{ml})$ & $\mathbf{7 6 . 5} \pm \mathbf{4 3 . 6}$ & $\mathbf{3 2 . 9} \pm \mathbf{1 8 . 6}$ & $\mathbf{0 . 0 0 1} * *$ \\
\hline AMH $(\mathrm{ng} / \mathrm{ml})$ & $\mathbf{0 . 6 3 5} \pm \mathbf{0 . 6 8 3}$ & $\mathbf{0 . 0 3 4} \pm \mathbf{0 . 0 2 3}$ & $\mathbf{0 . 0 0 1} * *$ \\
\hline
\end{tabular}

Data presented as mean \pm SE. NS: No significant differences $(p>0.05),(*)$ significant differences $(p<0.05),(* *)$ highly significant differences $(p<0.01)$. Independent $t$-test is statistically used to compare between patients and control group.

It is known that estradiol level is decreasing with age in females, corresponding to hormonal changes and loss of functional ovaries. In this study, there were highly significant differences $(\mathrm{p}<0.01)$ between the level of E2 in pre and post-menopausal female patients. As shown in Table-1, the concentration of E2 in the postmenopausal female patients was lower than its concentration in the pre-menopausal female patients $(32.9 \pm 18.6$ vs. $76.5 \pm 43.6 \mathrm{ng} / \mathrm{ml})$. Ginting [15] reported similar results to the current ones.

The reason for the difference in the level of hormones between the two stages of pre- and postmenopause is that some hormones are regulated according to feedback mechanisms. For example, elevated FSH and LH levels lead to inhibition of follicles development and reduction in the function of the ovaries, so that the AMH level falls down. Also the increase FSH level reflects a decline of estrogen and progesterone production. This study found that RA in women does not affect the rate of changes in the levels of reproductive hormones between the pre- and postmenopausal stages.

\section{Conclusions}

Rheumatoid arthritis is more prevalent in overweight and obese female patients and in those aged 50-60 years. The increase in the level of disease indicators (RF and Anti-CCP) among the postmenopausal female patients, even if it was not significant, indicates that the hormonal changes accompanying this stage may have a role in the development of the disease and the stimulation of the inflammatory condition,

\section{References}

1. Calabresi, E., Petrelli, F., Bonifacio, A.F., Puxeddu, I. and Alunno, A. 2018. One year in review 2018: pathogenesis of rheumatoid arthritis, Clin Exp Rheumatol, 36(2): 175-184.

2. Subhi, I.M. and Zgair, A.K. 2018. Estimation of Levels of Interleukin-1 beta and Interleukin-10 in Sera of some Iraqi Patients with Chronic Rheumatoid Arthritis, Iraqi Journal of Science, 59(3C): 1554-1559.

3. Aletaha, D. and Smolen, J.S. 2018. Diagnosis and management of rheumatoid arthritis: a review, Jama, 320(13): 1360-1372.

4. Scott, D.L., Wolfe, F. and Huizinga, T.W. 2010. Rheumatoid arthritis, Lancet, 376(9746): 1094108.

5. Pelechas, E., Kaltsonoudis, E., Voulgari, P.V. and Drosos, A.A. 2019. Laboratory and Immunological Tests in Rheumatology, Illustrated Handbook of Rheumatic and Musculo-Skeletal Diseases, Springer2019, pp. 23-44.

6. Favalli, E.G.,Biggioggero, M., Crotti, C., Becciolini, A., Raimondo, M.G. and Meroni, P.L. 2019. Sex and Management of Rheumatoid Arthritis, Clin Rev Allergy Immunol, 56(3): 333-345.

7. Alpizar-Rodríguez, D., Pluchino, N., Canny, G., Gabay, C. and Finckh, A. 2016. The role of female hormonal factors in the development of rheumatoid arthritis, Rheumatology (Oxford, England) 56.

8. Dashty Abass, A.B. and Khadeeja Ramadhan, Y. 2017. Prevalence of obesity in rheumatoid arthritis and its association with disease activity and latex positivity in a sample of patients in Erbil Zanco Journal of Medical Sciences, 1(2): 1726-1735.

9. Lahiri, M., Luben, R.N., Morgan, C., Bunn, D.K., Marshall, T., Lunt, M., Verstappen, S.M., Symmons, D.P., Khaw, K.T. and Wareham, N. 2014. Using lifestyle factors to identify individuals at higher risk of inflammatory polyarthritis (results from the European Prospective Investigation of Cancer-Norfolk and the Norfolk Arthritis Register-the EPIC-2-NOAR Study), Annals of the rheumatic diseases, 73(1): 219-226.

10. Lu, B., Hiraki, L.T., Sparks, J.A., Malspeis, S.,Chen, C.Y., Awosogba,J.A., Arkema, E.V., Costenbader, K.H. and Karlson, E.W. 2014. Being overweight or obese and risk of developing 
rheumatoid arthritis among women: a prospective cohort study, Annals of the rheumatic diseases, 73(11): 1914-1922.

11. Feng, J., Chen, Q., Yu, F., Wang, Z., Chen, S., Jin, Z., Cai, Q., Liu, Y. and He, J. 2016. Body Mass Index and Risk of Rheumatoid Arthritis: A Meta-Analysis of Observational Studies, Medicine (Baltimore), 95(8): e2859.

12. Gharbia, O., El-Bahnasawy, A. and Okasha, A. 2018. Impact of obesity on rheumatoid arthritis: Relation with disease activity, joint damage, functional impairment and response to therapy, International Journal of Clinical Rheumatology, 13(6): 346.

13. Muataz Mohammed Al-Taee, Duaa Ibrahim Mohmood and Mayada Mahmood Muhammed. 2019. Determining Levels of Rheumatoid Factor (RF) and C - reactive protein (CRP) in a Blood Sample of Iraqi Patients with Rheumatoid Arthritis (RA), Al-Nisour Journal for Medical Sciences, 1(1): 139-133.

14. Mohammed Jasim, Ali Ibrahim Ali. 2011. Performance of Anticyclic Citrullinated Peptide Antibodies versus Rheumatoid Factor in diagnosis of Rheumatoid Arthritis, Diyala Journal of Medicine, 1(1):81 -90.

15. Ginting, S.F. Syukur,S. Ibrahim, S. Tjong, D.H. Fachrial, E. 2015. Lipid profile and estradiol analysis between pre-menopause and post-menopause women in Medan areas of North Sumatera, Indonesia, Journal of Chemical and Pharmaceutical Research, 7(10): 505-508.

16. Cevik,R. Em, S. Gur, A. Nas, K. Sarac,A.J. Colpan, L. 2004. Sex and thyroid hormone status in women with rheumatoid arthritis: are there any effects of menopausal state and disease activity on these hormones?, International journal of clinical practice, 58(4): 327-32. 